\title{
Genomic, RNA, and ecological divergences of the Revolver transposon-like multi-gene family in Triticeae
}

\author{
Motonori Tomita ${ }^{1 *}$, Asuka Okutani $^{1}$, Avigdor Beiles $^{2}$ and Eviatar Nevo ${ }^{2}$
}

\begin{abstract}
Background: Revolver is a newly discovered multi-gene family of transposable elements in the Triticeae genome. Revolver encompasses 2929 to 3041 bp, has 20 bp of terminal inverted repeated sequences at both ends, and contains a transcriptionally active gene encoding a DNA-binding-like protein. A putative TATA box is located at base 221, with a cap site at base 261 and a possible polyadenylation signal AATAAA at base 2918. Revolver shows considerable quantitative variation in wheat and its relatives.

Results: Revolver cDNAs varied between 395 and 2,182 bp in length. The first exon exhibited length variation, but the second and third exons were almost identical. These variants in the Revolver family shared the downstream region of the second intron, but varied structurally at the $5^{\prime}$ first exon. There were 58 clones, which showed partial homology to Revolver, among 440,000 expressed sequence tagged (EST) clones sourced from Triticeae. In these Revolver homologues with lengths of 360-744 bp, the portion after the 2nd exon was conserved (65-79\% homology), but the 1st exon sequences had mutually low homology, with mutations classified into 12 types, and did not have EST sequences with open reading frames (ORFs). By PCR with the 3'-flanking region of a typical genomic clone of Revolver-2 used as a single primer, rye chromosomes $1 \mathrm{R}$ and $5 \mathrm{R}$ could be simultaneously identified. Extensive eco-geographic diversity and divergence was observed among 161 genotypes of the single species Triticum dicoccoides collected from 18 populations in Israel with varying exposures to abiotic and biotic stresses (soil, temperature, altitude, water availability, and pathogens).

Conclusions: On the base of existing differences between Revolver variants, the molecular markers that can distinguish different rye chromosomes were developed. Eco-geographic diversification of wild emmer $T$. dicoccoides in Israel and high Revolver copy numbers are associated with higher rainfall and biotic stresses. The remarkable quantitative differences among copy numbers of Revolver in the same species from different ecosystems suggest strong amplification activity within the last 10,000 years. It is the interesting finding because the majority of Triticeae high-copy transposable elements seem to be inactive at the recent time except for BARE-1 element in Hordeum and the fact might be interesting to perceive the processes of plant adaptive evolution.
\end{abstract}

\section{Background}

In the higher plants, only a small percentage of the genome is required for maintenance of life [1,2], and transposable elements and the sequences derived from them are scattered in the other highly repetitive DNA regions [3-6]. The transposable elements are classified into the class I transposable elements (retrotransposons), which

\footnotetext{
* Correspondence: tomita@muses.tottori-u.ac.jp

'Molecular Genetics Laboratory, Faculty of Agriculture, Tottori University, Tottori 680-8553, Japan

Full list of author information is available at the end of the article
}

use a transcript as a template and transfer replicatively, and class II transposable elements (transposons), which transfer DNA by the cut-and-paste mechanism. It is believed that class I long terminal repeat (LTR) retrotransposons and class II miniature inverted repeat transposable elements (MITEs) are major components of the plant genome [7-10]. Such transfer factors can be used as the source of mutations for DNA marker development or gene functional analysis; the transposable elements with a high number of copies can become the entry points for PCR during DNA marker development,
Ciomed Central

() 2011 Tomita et al; licensee BioMed Central Ltd. This is an Open Access article distributed under the terms of the Creative Commons Attribution License (http://creativecommons.org/licenses/by/2.0), which permits unrestricted use, distribution, and reproduction in any medium, provided the original work is properly cited. 
and the transposable elements that cause gene disruption enable tagging of genes and contribute to functional genome research $[11,12]$. However, the sequences of regions of repetitive DNA other than the known transposable elements $[13,14]$ are still undetermined, while in the region of repetitive DNA regarded as junk DNA, it has been found that the RNA genes that perform epigenetic regulation of gene expression are also scattered [15-17]. Investigation of the unknown factors in repetitive DNA regions is also important as a key to understanding the mechanisms of genome control and phenotypic expression.

The first authors recently reported a new transposonlike gene, named Revolver, in Triticeae [18,19]. A part of the reiterated sequence $(89 \mathrm{bp})$ specific to the rye genome was cloned by the genome subtraction technique, which deducts the sequence in common with bread wheat from the rye genome [20]. In order to determine the entire structure of this reiterated sequence, the $\lambda$ FixII genomic library of the rye-inbred line was screened by using $89 \mathrm{bp}$ of the repetitive clone as a probe, and the base sequence of a region of about $21.6 \mathrm{~kb}$ was decoded in three lambda clones. As a result, the insertion-type consensus sequence ( $92 \%$ homology) with a full-length sequence of 3,041 bp sandwiched between 20 bp of specific terminal inverted repeat (TIR) sequence was determined and shown to be similar to the class II transposable elements [18,21-26]. Revolver contains one gene that codes for an open reading frame (ORF) of a deduced 139 amino acid residue that is actively transcribed into mRNA. The sequence of the $20 \mathrm{bp}$ inverted repeat sequence at both ends is different from that of the known transposons represented by $h A T$, CACTA, and Mutator, and $10 \mathrm{bp}$ of the tandemly repeated sequence is also repeated in the subterminal region.

In a genomic DNA clones of rye that show homology to Revolver, great structural variation in the region ranging from the first exon to the first intron had arisen and four sequences thought to be nonautonomous factors for Revolver were found. Revolver produces $0.7 \mathrm{~kb}$ of mRNA and is conserved in Triticeae. A putative TATA box is located at base 221, with a cap site at base 261 and a possible polyadenylation signal AATAAA at base 2918 [18]. On the other hand, the full length of the nonautonomic factor is 2665 to $4269 \mathrm{bp}$. The nonautonomic factor has a 37-149-bp homologous region upstream from the transcription start site containing a TIR at the 5' end and a 1294-2112-bp region covering from around the second exon to the 3' end on the 3' side. A region of 549-2007 bps located between them (equivalent to the region from the first exon to the first intron) is destroyed. In rye and barley, the nonautonomic factors sharing each end with Revolver are considered to exist within it [19].
The number of copies in Triticeae was computed by Southern blot analysis and slot blotting techniques by using cDNA of Revolver as the probe. Consequently, extremely high numbers of Revolver (20,000 copies) have been shown to exist in Dasypyrum villosum and Secale sp., as well as in diploid species such as Triticum monococcum, which is the ancestor of bread wheat and tetraploid species such as emmer wheat, with around 10,000 copies. However, the number of copies is extremely low in hexaploid bread wheat. There has been a large quantitative change during the evolution of Triticeae resulting in amplification of Revolver in some species and its disappearance in bread wheat [18]. The considerable quantitative variability of Revolver among the wheat-related species strongly indicates its propagation or differential loss, activity, and diversity in recent evolutionary times.

In this paper, the structural divergence of Revolver in genomic DNA and RNA was analyzed, and length variants of the Revolver family were used as chromosome tags to search the publicly disclosed expressed sequence tag (EST) database of the 440,000 Triticeae EST sequences for Revolver homologues. Moreover, we examined the quantitative variations of Revolver in 161 T. dicoccoides accessions [27] representing 18 populations collected from various locations in Israel, which encompass a wide range of ecologic conditions of soil, temperature, altitude, and water availability, to determine the effects of ecologic stress on quantitative variation.

\section{Results and Discussion}

\section{Structural diversity of Revolver mRNA}

Revolver, encompassing a 3,041 bp sequence, has $20 \mathrm{bp}$ of TIR sequences and contains a transcriptionally-active gene, consisting of three exons (342 bp, $88 \mathrm{bp}$, and 296 bp) and two introns (750 bp and 1,237 bp) (Figure 1), and encodes a DNA-binding-like protein [18]. Fifty cDNA clones of the Revolver family were obtained from self-fertile rye (homozygous genotype), and a structural analysis was performed. The total lengths of typical Revolver cDNAs were 665 to 723 bp in 40 clones out of 50 cDNAs, and they were classified into three subfamilies (I, II, and III) in which the regions of the second and third exons were almost identical, while the region of the first exon exhibited a low homology of $60 \%$ among the subfamilies because of duplication or deletion (Figure 1 and Additional file 1). The homologies in the subfamilies were $89 \%$ ( I), 97\% ( II), and 93\% ( III), and the homologies between the subfamilies were $75 \%$ for subfamily I and subfamily III, $80 \%$ for subfamily I and subfamily III, and 76\% for subfamily I and subfamily III. Comparing sequences between the exons, the second exon (89 to $92 \mathrm{bp}$ ) and the third exon (293 bp) 


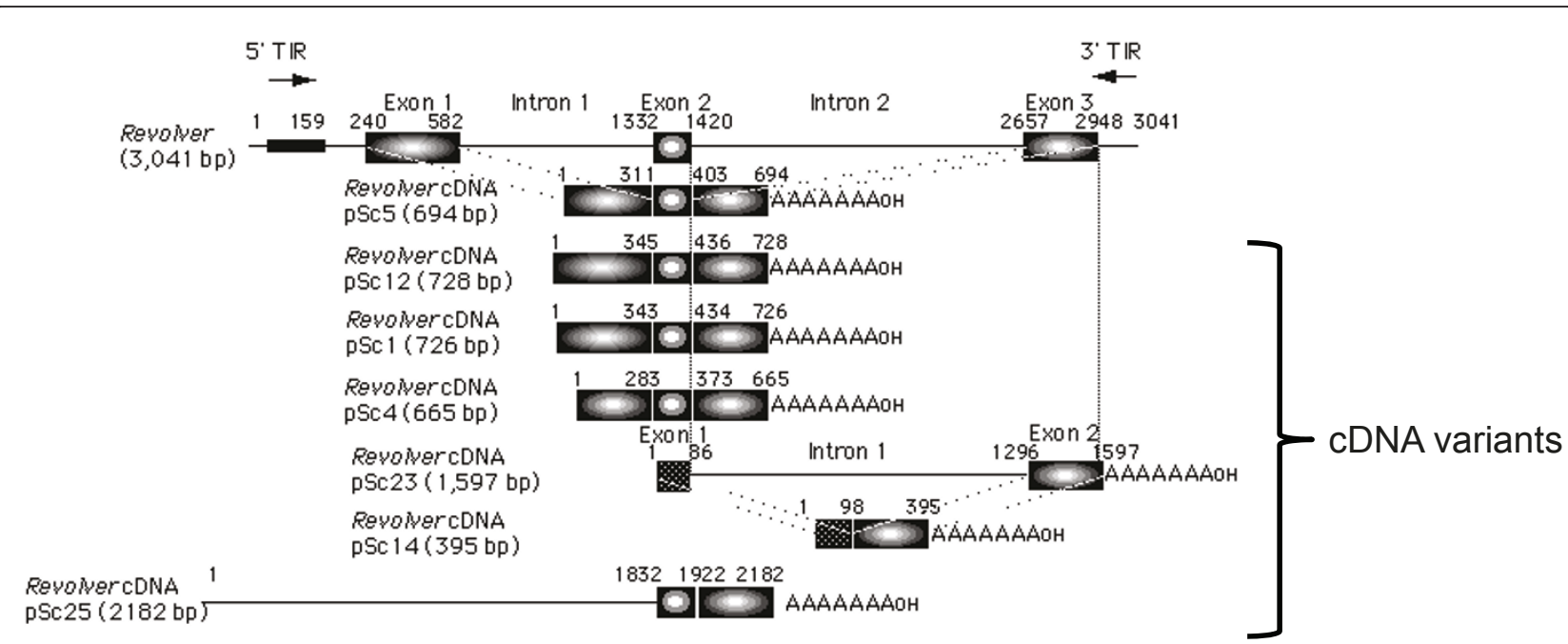

Figure 1 Multiple classes of Revolver mRNA. The structure of several Revolver cDNA clones (AB124645, 124665-124669) isolated from rye in comparison with Revolver genomic sequence.

exhibited high homologies of 91 to $95 \%$ between the different subfamilies. In contrast, the first exon exhibited high homology within the subfamilies (I: 98\%, II: 99\%, and III: 99\%); but the homologies between subfamilies were low (63\% between I and II, $64 \%$ between I and III, and $67 \%$ between II and III). In the first exon, partial deletions and mutations of different lengths were found in the base sequences of the three classes. Thus, the classification of the cDNA corresponds to the structural divergence of the first exon. Because repetitive sequence units composed of 8 to $14 \mathrm{bp}$ are present in the same direction in the first exon, a nonhomologous recombination between alleles might have caused various structural mutations.

Moreover, cDNAs exhibiting completely different structures at the first exon were found in $50 \mathrm{cDNA}$ clones from self-fertile rye (Figure 1). Among them, five cDNAs had a total length of $1,597 \mathrm{bp}$ and contained the second intron (1,210 bp) and the third exon (301 bp) of Revolver, but at the 5' terminus, they had an $86 \mathrm{bp}$ sequence that was not observed in Revolver. On the other hand, four cDNA clones had a total length of 395 bp and lacked the second intron compared to the cDNA clones of 1,597 bp described above. Meanwhile, another cDNA clone (total length of 2,182 bp) had the second exon (90 bp) and the third exon (260 bp) of Revolver, but the region corresponding to the first exon was extremely long and had no homology with the other cDNA clones. As stated above, the members of the Revolver family, having a common structure downstream of the second intron, may easily undergo various structural changes at the 5' first exon and then become divergent and show different lengths. Such structural diversities were found in the first exon of the Revolver genes that were obtained from the self-fertile pure rye strains, and these structural diversities may be useful for development of DNA markers in the rye genome.

Furthermore, Revolver cDNAs were recovered from $S$. silvestre, D. villosum, T. monococcum, and Aegilops tauschii after isolation by RT-PCR with 22-mer primers used at both ends. The majority belonged to subfamilies I $(47 \%)$ or II $(27 \%)$ of $S$. cereale, indicating that two major subfamilies were conserved within the Triticum species. Among the Revolver mRNAs, subfamily I contained a single ORF encoding 139 amino acid residues [18], which was conserved in the Triticum species with 98\% homology. The Revolver ORF was integrated into the pET-32 vector, and the encoded protein fused with thioredoxin was produced in Escherichia coli (Figure $2 \mathrm{~A})$. The molecular weight of the fused protein was about 50,000, and that after treatment with Factor Xa was about 30,000 (Superdex 75 gel filtration). The protein structure encoded by Revolver was predicted by the Protein Folding Recognition program Robetta. As shown in Figure 2B, the Revolver ORF includes the c2rf9 motif of a kinase domain.

\section{Expressed sequence tag homologues of Revolver}

In this study, we searched the publicly disclosed EST database for Revolver homologues. Of the 440,000 Triticeae EST clones in GenBank having mainly T. aestivum as their source, 63 clones showed partial homology with Revolver (46 T. aestivum, 6 S. cereale, 4 T. monococcum, 2 Ae. speltoides, and $5 \mathrm{H}$. vulgare) (Figure 3). These Revolver homologues were about 360-744 bp in length. Only two clones, which were from T. aestivum (615 bp) 


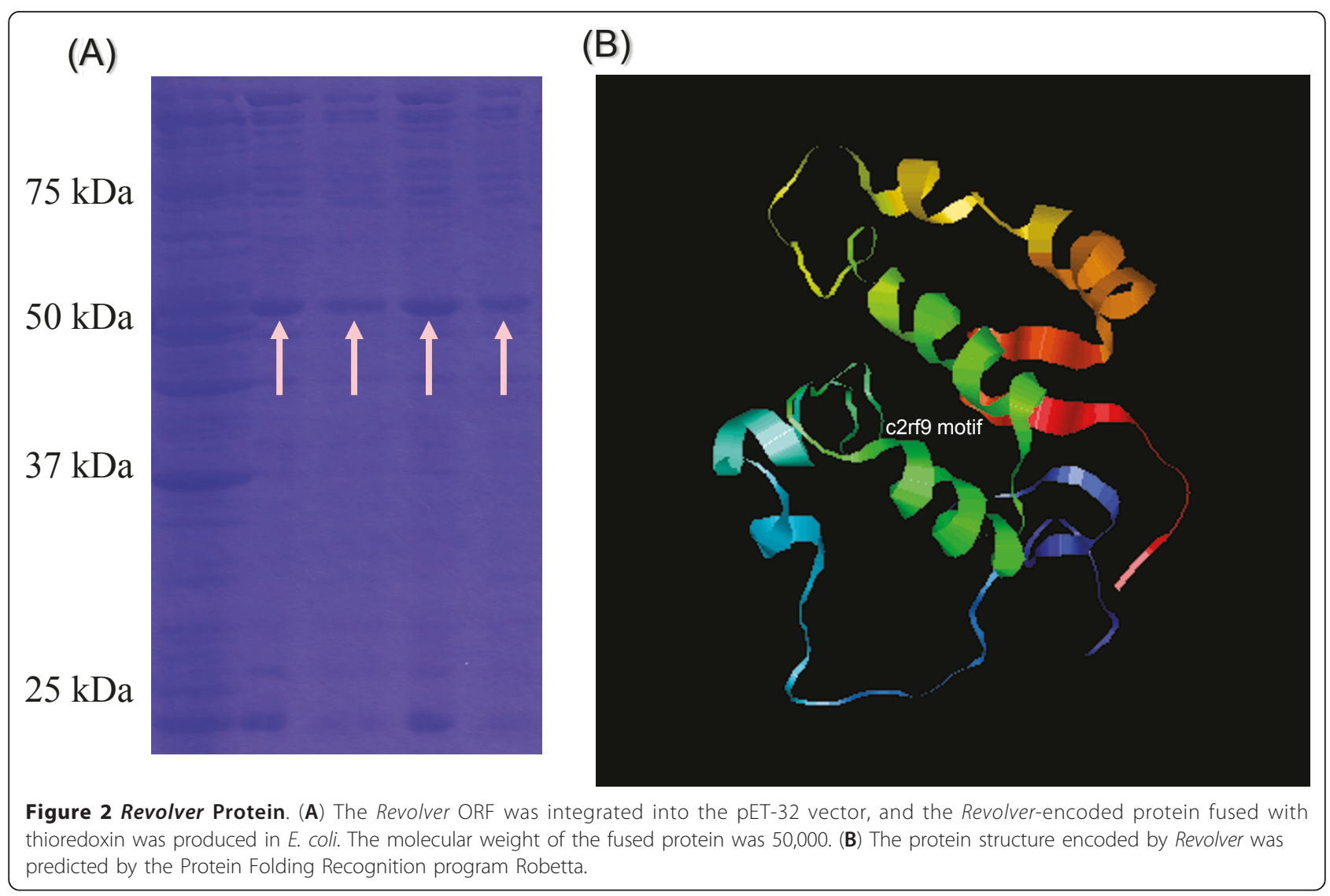

and $H$. vulgare (713 bp), showed similarity with Revolver cDNA across its entire length (Figure 4B). Sequences downstream of exon 2 were conserved (about $65-79 \%$ identity) in other EST clones (Figure 3B), although they had either low homology in the 5' regions containing exon 1 (Figure 3A), or were missing in the upstream sequence. S. cereale, Einkorn wheats, and Ae. tauschii, all of which showed high levels of Revolver transcription by northern blotting, have cloned cDNA from the Revolver ORF coding for the 139 amino acids (Class I) together with 2 cDNAs differing in exon 1 sequences (Class II, III). The 615-bp EST from T. aestivum, which had the highest sequence similarity to Revolver, was close to Class II (Figures 3A and 4B); however, the exon 1 region was only $60 \%$ homologous. Other EST clones containing the exon 1 region matched none of the three classes and were very different from each other (Figures 3A and 4B). Revolver-like EST clones from T. aestivum were classified into at least 12 types on the basis of mutations in the exon 1 region, and these EST clones exhibited large genetic variation (Figure 3A). Exon 2 and exon 3 regions showed three major clusters according to wheat, rye and barley species (Figure 3B). Thus, Revolver-like transcripts do exist in T. aestivum, although their proportion among total EST clones is extremely small, and given that they include variants with large mutations, no true Revolver genes were present. We hypothesize that Revolver was lost in T. aestivum because it lost its ability to be reinserted. On the other hand, no Revolver homologues were found in the Oryzeae EST database. In addition, Revolver was not detected in the rice genome by Southern blot analysis.

\section{Development of chromosomal markers with Revolver}

A typical genomic clone of Revolver (Revolver-2 [18]) was located in this study on the rye $7 \mathrm{R}$ chromosome because 492 bp of DNA was amplified only from the rye 7R chromosome addition line by PCR using the 5'-flanking region of Revolver-2, 5'-GCCTTTCGGCCTTC CTCTCAGGCGG-3', and its internal sequence of 5'GTACTTGGCATCGGTAGATGTTCGG-3', as the primers. PCR was performed then with the 3'-flanking region derived from the typical genomic clone of Revolver- 2 as a single primer, and 4 DNA fragments $(2.3 \mathrm{~kb}$, $2.8 \mathrm{~kb}, 3.3 \mathrm{~kb}$, and $4.3 \mathrm{~kb}$ ) were amplified from the rye genome, but nothing was amplified from the wheat genome (Figure 4A). Furthermore, when PCR was performed with the same primer and genomic DNA from rye chromosome addition lines as a template, DNA fragments of $2.8 \mathrm{~kb}, 3.6 \mathrm{~kb}$, and $4.3 \mathrm{~kb}$ were amplified from 


\section{Revolver-like EST}

\section{(A) Exon 1 \\ (B) Exon 2 and 3}

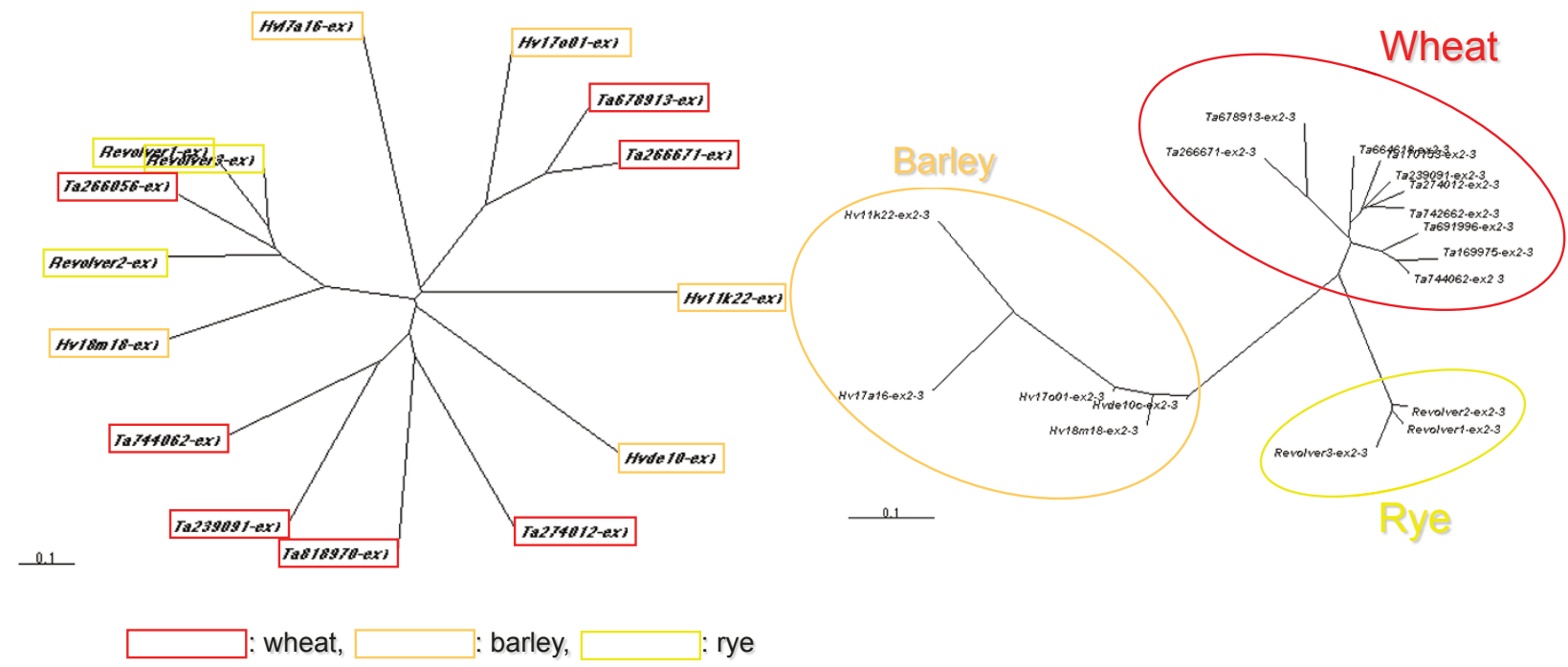

Figure 3 Neighbor-joining tree of authentic Revolver cDNAs and Revolver-like Triticeae ESTs. Two phylogeneric trees were constructed on the exon 1 region (A), and on the exon 2 and exon 3 regions (B), respectively. Revolver-like Triticeae ESTs were diverged into at least 12 types with regardless to species on the basis of mutations in the exon 1 region. On the other hand, the phylogeneric tree on the exon 2 and exon 3 regions showed three major clusters according to wheat, rye and barley species.

the $1 \mathrm{R}, 5 \mathrm{R}$, and $6 \mathrm{R}$ chromosome addition lines, respectively (Figure 4B). PCR amplification with this single primer identified rye chromosomes $1 \mathrm{R}$ and $5 \mathrm{R}$ simultaneously. Each DNA fragment derived from the chromosome addition lines and four types of DNAs amplified from the rye genome were sequenced (Additional file 2); and the variants were shown to have the downstream region of the second intron, but they had structural modifications at the 5' first exon region as in the cDNAs (Figure 4B). Such a difference in length in Revolver allows the development of rye chromosome markers.

Revolver-3 [18] comprises a total length of 4,269 bp, and at the 3' end it has a region of 2,112 bp from the middle of the first intron of Revolver through the third exon and reaches the 3'-terminal region (Figure 4B). In this study, Revolver-3 was shown to be localized on the 6R chromosome because it was amplified with the 3'flanking region primer of Revolver-2 only from the rye 6R chromosome addition line. Furthermore, Revolver-5 located on the rye $1 \mathrm{R}$ chromosome had a total length of $2,665 \mathrm{bp}$, while at the 3 ' side it had a region of $1,826 \mathrm{bp}$ extending from immediately before the second exon to the 3' terminus of Revolver (Figure 4A and 4B). At its 5' side, the region homologous to Revolver is limited to only $37 \mathrm{bp}$ at the terminus; but a region of about 670 bp is homologous to Revolver-4 [18], which consists of $3,219 \mathrm{bp}$, and at the 3 ' end it has a region of $1,806 \mathrm{bp}$ ranging from immediately before the second exon to the 3' terminus of Revolver (Figure 4B). Finally, Revolver-6 located on the rye $5 \mathrm{R}$ chromosome (Figure $4 \mathrm{~A}$ ) had a total length of 3,503 bp, and at the 3' side, it had a region of 1,294 bp from the middle of the second intron to the 3' terminus of Revolver. However, at the 5' side, there was no region homologous to Revolver, and the 121 bp sequence at the 5' terminus was homologous to Revolver-4 and Revolver-5 (Figure 4B).

As mentioned above, the members of the Revolver family showed considerable length variation which was attributed to structural changes in the first exon. Such a divergence in length is also found in some transposons, the CACTA family [28], the Mutator family [29], and the MITE family [10], but no homology was detected between Revolver and any of these. If the Revolver family is a transposable element, these variants are assumed to be nonautonomous elements. Revolver showed a variability that was considerably larger than the others. With PCR primers comprising the sequences flanking the length variants of Revolver scattered in the genome, the chromosome on which each Revolver is located can be 


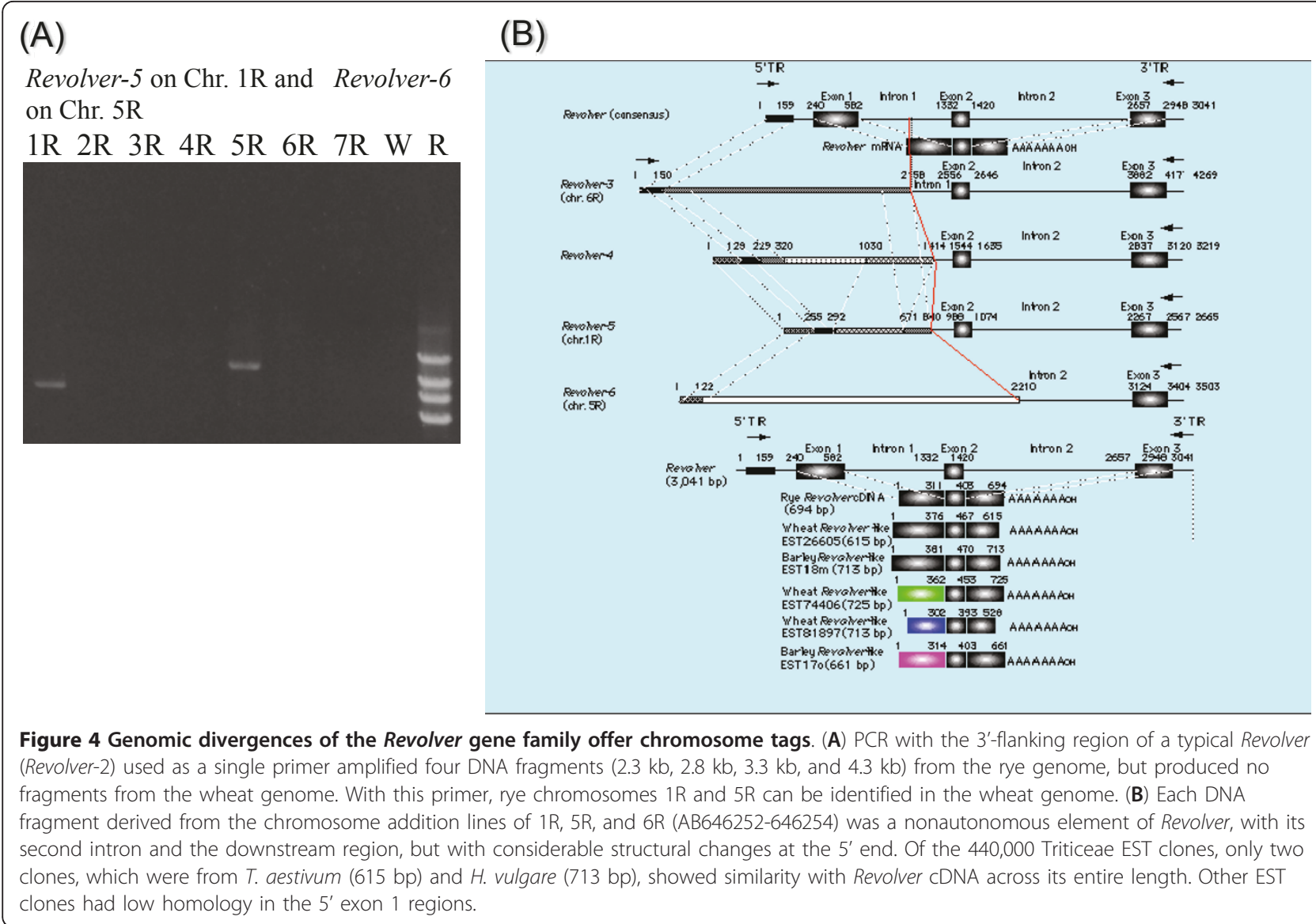

determined or tagged, and such PCR primers can be utilized for detection and identification of the chromosomes.

\section{Quantitative variation of Revolver in wild Emmer wheat of Israel}

Among the Triticum species, Revolver shows the highest copy number $(19,000)$ in $S$. cereale, and the lowest copy number $(2,000)$ in $T$. aestivum [18]. In this study, the copy numbers of Revolver in wild emmer wheat were estimated by slot blot analysis. The Revolver cDNA subfamily I (pSc5, 694 bp), which is conserved in Triticum species, was used as a probe. Wild emmer wheat, Triticum dicoccoides (AABB), is a tetraploid progenitor from which modern tetraploid and hexaploid cultivated wheat is derived. $T$. dicoccoides deserves to be considered as a potential genetic resource for cereal improvement because wild emmer harbors rich genetic diversity for multiple disease resistances, agronomic traits of economic significance, and environmental adaptations [27]. The center of distribution and genetic diversity of $T$. dicoccoides is found in the catchment area of the upper Jordan Valley in Israel and its vicinity [30,31]. We examined the copy number of Revolver in wild emmer wheat
T. dicoccoides in 18 populations (161 genotypes), representing a wide range of ecologic conditions of soil, temperature, and water availability in Israel (Figure 5, Additional files 3 and 4).

All populations were rich in copy number (Additional file 4 and Figure 5). Most populations had a large variance in copy number from around 1,000 to 30,000, despite the predominantly self-fertilizing nature of this species. The populations in the catchment area of Yehudiyya, Gamla, Tabigha, and Rosh-Pinna, where semihumid and warm climatic conditions prevail, showed high copy numbers, which were almost over 7,000 per haploid genome and included several genotypes having around 20,000 copies (Figure 5). Several populations had higher numbers than 1,100: Yehudiyya shade or sun, Amirim, Bet Oren, Bat Shelomo, Gamla, Giv'at Koah, and J'aba. In the marginal mesic areas of Amirim, Bet Oren, Bat Shelomo, and Giv'at Koah, the copy numbers were very stable: between 6,000 and 8,000. In contrast, the populations of the marginal steppic areas, such as, Mt. Gerizim, Kokhav-Hashahar, and Gitit, included several genotypes with low copy numbers less than 1,000 (Figure 5). This pattern suggests that high Revolver copy numbers in northern wild emmer populations appear to 


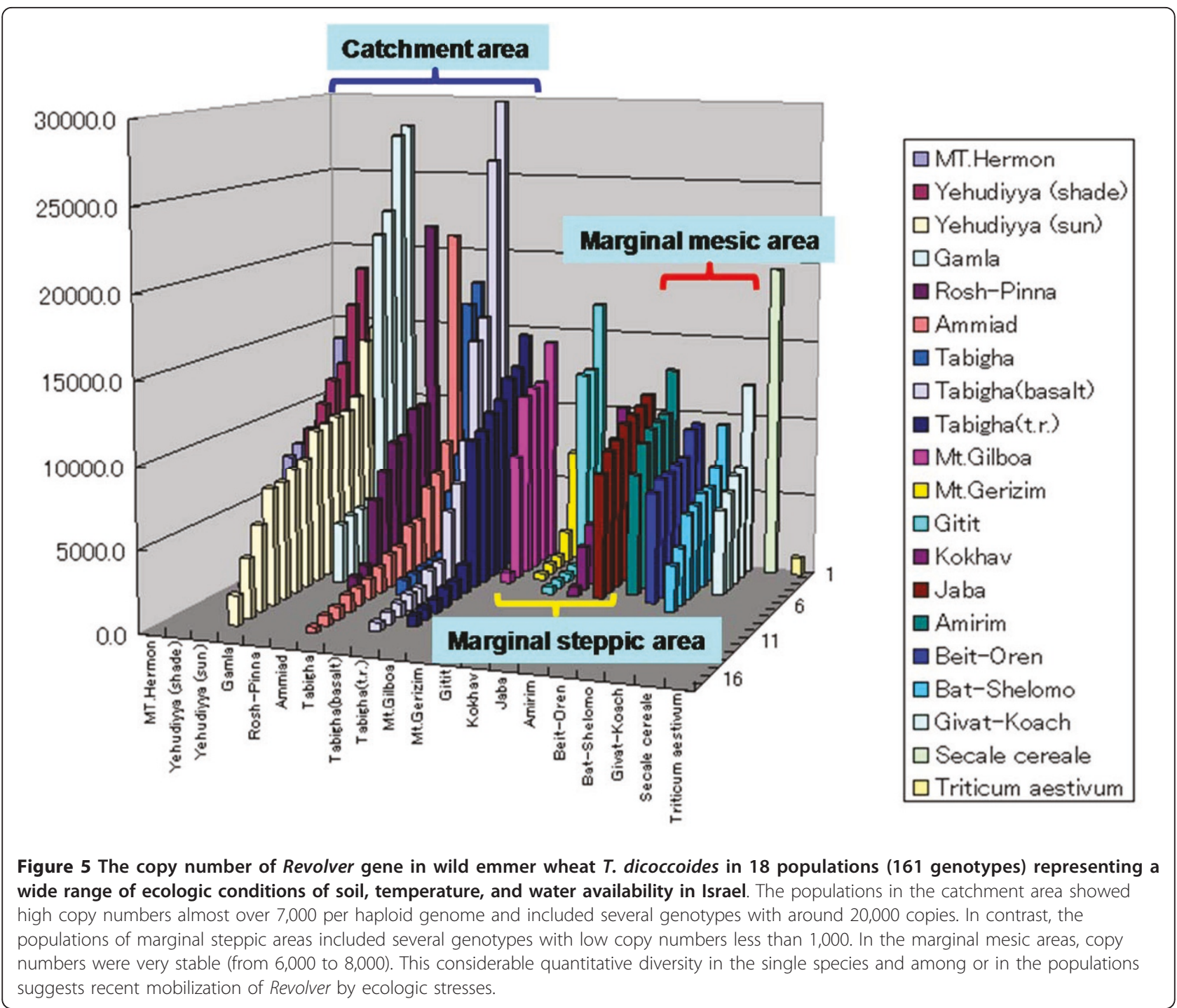

be associated with biotic stresses, e.g., pathogens and population densities.

The copy numbers in the populations of Yehudiyya, Ammiad, and Tabigha showed a broad range (between 20,000 and less than 1,000) (Figure 5). Some populations displayed gradual variations from low to high (e.g., Ammiad, Yehudiyya sun and Yehudiyya shade, J'aba, Amirim, Bet Oren, Bat Shelomo, and Giv'at Koah). About half of the populations had polymodal distribution. Some populations were extremely bimodal: Gamla (4 genotypes were from 3,000-4,000 and 4 genotypes were from 20,000-30,000) and Gitit (4 genotypes around 500 and 3 genotypes above 12,000) (Figure 5). The different modes of distributions among the populations suggest differences in Revolver's mobility in each population. In barley, the selective pressures under hot, dry desert conditions significantly correlate with increasing copy numbers of retrotransposon $B A R E-1$ [32,33] and microsatellite sequences [34]. Revolver showed a variance considerably larger than $B A R E-1$. The propagation activity of Revolver also might be responsive to both regional and local environmental conditions and its extensive quantitative diversity in the single species $T$. dicoccoides as well as among its local populations at microsites, such as, Yehudiyya and Tabigha, suggest the recent mobilization of Revolver by ecological stresses.

Our results show that 6,000 or more copies of Revolver exist in the native line from the area that has much precipitation and an average yearly temperature around $20^{\circ} \mathrm{C}$; and there was a line that contained as many as 20,000 copies, as does rye wheat. On the other hand, only a few hundred copies existed in the large majority of the lines in the area where the hot-dry monsoon occurred frequently (85 days per year) and the area where the number of sultry nights reached 80 days per year. The remarkable quantitative differences in Revolver 
within the same species growing in different ecosystems illustrate a strong amplification activity within the last 10,000 years.

\section{Conclusions}

Transposon-like factor Revolver (US granted patent 7351536), which is $3041 \mathrm{bp}$ in length and includes a 20bp TIR on either end, is dispersed within the genomes of Triticum species. Revolver contains an ORF coding for an amino acid sequence of 139 residues that is conserved among Triticum species. In S. cereale, a $0.7-\mathrm{kb}$ mRNA is actively transcribed from this ORF. Southern blot analysis revealed multiple copies of Revolver within Secale and Dasypyrum species, as well as some copies in diploid species, such as, Einkorn wheat and Aegilops tauschii, and in tetraploid species, such as, Triticum durum. In contrast, copies were not found in the hexaploid species $T$. aestivum, in which transcribed products were also undetected by northern blot analysis. Through evolution, Revolver has been amplified in several Triticum species while being lost in others. It is therefore a useful gene for the development of DNA markers for Triticeae-related species and for use in T. aestivum breeding.

The novel high-copy Revolver family is transcriptionally active in rye. Some of the transposon-like elements exist in high copy numbers in the genomes of most eukaryotes, but the great majority of them are inactive, and only a small portion of them retain the ability to transpose $[35,36]$. Very few transposons have been shown to be transcriptionally active. A copia-like retroelement BARE-1 dispersed in $10 \%$ of the barley genome [37] is transcribed in somatic tissues [38]. Some LTR retrotransposons such as tobacco Tnt1, Tto1, and $O A R E-1$ that are largely inactive, can be transcriptionally activated under conditions of biotic and abiotic stress, including wounding, oxidative stress, and pathogen infection $[39,40]$. After stress-induced transcription, the rice LTR retrotransposon Tos17 increased in genomic copy number [41]. In maize, a survey of more than $4 \times$ $10^{5}$ ESTs identified only 56 retrotransposon cDNAs, supporting the notion that most retrotransposons are inactive [6]. Furthermore, most of these maize sequences are derived from the low-to-middle repetitive LTR retrotransposons and not from the very high copynumber elements that have been responsible for doubling the size of the maize genome in the past 5-6 million years. In humans, only 30-60 L1 elements out of 5 $\times 10^{5}$ comprising $45 \%$ of the genome are thought to be active [42]. In general, high-copy retrotransposons show low-level activity except for BARE-1. Like BARE-1, highly repetitive Revolver is transcribed.

A transcriptionally active Revolver gene is well conserved among the Triticeae members. The methylated and heterochromatic state of most transposons can cause them to change sequences more rapidly than genes $[43,44]$. For example, regulation at any stage of the replication cycle for retrotransposons (transcription, translation, reverse transcription, and integration of cDNA elements) can limit transposition. Furthermore, the paucity of maize retrotransposon-derived ESTs indicates that some epigenetic mechanisms might have been repressing the transcription of a large fraction in the genome $[15,45,46]$. In contrast to these silenced retrotransposons, Revolver is transcriptionally active (Figure 1) and might have retained transcriptional activity during the long evolution of Triticeae. The predicted protein encoded by Revolver subfamily I includes a c2rf9 motif of a kinase domain and may serve as a transcription factor among this family. The considerable variation in Revolver copy numbers among $T$. dicoccoides indicates their propagation activity during the last 10,000 years of $T$. dicoccoides evolution. The name of the novel transposon-like gene Revolver means a dynamic factor in constructing genomes through evolution of the Triticeae, associated with ecological stresses, and presumably navigated adaptively by natural selection.

\section{Methods}

\section{Structural diversities of Revolver mRNA}

Revolver cDNAs were obtained from self-fertile rye, and structural analysis of the cDNA clones was performed. The primers for amplification of Revolver cDNA were designed from both ends of a full-length cDNA clone. Total RNA for RT-PCR extracted from seedlings was treated with DNase I. First-strand cDNAs were synthesized by AMV reverse transcriptase (Life Science) with an oligo (dT) primer. Reaction mixtures contained 10 ng of template cDNA, 50 pmoles of each primer (5'GGCACGAGGGTACGAGTCCGAG-3', 5'-GGCACAACTCATGTAAAAGAGGG-3'), $0.4 \mathrm{mM}$ dNTPs, $1 \times$ LA PCR buffer II, $2.5 \mathrm{mM} \mathrm{MgCl}_{2}$, and $0.5 \mathrm{U}$ of $L A T a q$ polymerase (Takara) in a volume of $25 \mu \mathrm{L}$. The PCR reaction program consisted of 30 cycles of $30 \mathrm{sec}$ at $95^{\circ}$ $\mathrm{C}, 30 \mathrm{sec}$ at $63^{\circ} \mathrm{C}$, and $1 \mathrm{~min}$ at $72^{\circ} \mathrm{C}$. The RT-PCR products were purified, ligated to the pGEM-T vector (Promega), and sequenced.

\section{Revolver Protein}

The Revolver ORF in cDNA subfamily I (pSc5) was excised by restriction enzyme $\mathrm{Sal}$ I and Nco I and integrated into the plasmid vector pET-32a $(+)$ that had also been digested by $\mathrm{Sal}$ I and Nco I. The plasmid was transformed into E. coli BL21 (DE3) cells containing pLysS. The cells were grown in 2YT medium containing carbenicillin and chloramphenicol. The Revolver protein was induced by $1 \mathrm{mM}$ IPTG, and the culture was grown at $20^{\circ} \mathrm{C}$ overnight. Culture at $37^{\circ} \mathrm{C}$ resulted in 
production of an inclusion body. The Revolver protein fused to thioredoxin and his•tag was purified by nickel chelating affinity chromatography followed by POROS CM chromatography. After treatment with Factor Xa protease, the enzyme was subjected to Superdex 75 gel filtration. The protein structure encoded by Revolver was predicted by the Protein Folding Recognition program Robetta (http://robetta.bakerlab.org/).

\section{Expressed sequence tag homologues of a new class of transposon Revolver}

In this study, we searched the publicly disclosed EST database of Triticeae for Revolver homologues using a default cutoff expectation value of $<\mathrm{e}^{-20}$. Nucleotide sequences were compared with sequences in the non-redundant GenBank+EMBL+DDBJ databases with BLASTN homology search software [47]. Sequence alignment was determined with the computer program DNASIS Pro version 2.10 (Hitachi, Tokyo, Japan). A nonrooted phylogenetic tree was constructed with MEGA version 4.0.2 [48]. The neighbor-joining method [49] was conducted with Kimura's 2-parameter distances [50]

\section{Use of Revolver to generate chromosomal markers}

The single primer for amplification of Revolver genomic DNA was designed from the 3'-flanking region of a typical clone of Revolver (Revolver-2). Reaction mixtures contained $10 \mathrm{ng}$ of template genomic DNA, 50 pmoles of single primer (5'-GTAGTCGTCAGGAGTCCTCACCA3'), $0.4 \mathrm{mM}$ dNTPs, $1 \times$ LA PCR buffer II, $2.5 \mathrm{mM}$ $\mathrm{MgCl}_{2}$, and $0.5 \mathrm{U}$ of $L A T a q$ polymerase (Takara) in a volume of $50 \mu \mathrm{L}$. The PCR reaction program consisted of 30 cycles of $30 \mathrm{sec}$ at $95^{\circ} \mathrm{C}, 1 \mathrm{~min}$ at $55^{\circ} \mathrm{C}$, and $3 \mathrm{~min}$ at $72^{\circ} \mathrm{C}$. The four types of PCR products $(2.3 \mathrm{~kb}, 2.8 \mathrm{~kb}, 3.3$ $\mathrm{kb}$, and $4.3 \mathrm{~kb}$ ) amplified from the rye genome and rye chromosome addition wheat genomes were purified, ligated to the pGEM-T vector (Promega), and sequenced.

\section{Diversity of Revolver in wild Emmer wheat of Israel}

In this study, we examined the copy number of Revolver by slot blot analysis in $161 \mathrm{~T}$. dicoccoides genotypes representing 18 populations collected from various locations in Israel, which cover a wide range of ecologic conditions of soil, temperature, altitude, water availability, and abiotic stresses. The collections were from 14 locations in Israel, namely, Mt. Hermon, Yehudiyya, Gamla, Rosh-Pinna, Tabigha, Mt. Gilboa, Mt. Gerizim, Gitit, Kokhav-Hashahar, J'aba, Amirim, Bet Oren, Bat Shelomo, and Giv'at Koah.

Total DNAs isolated from $161 \mathrm{~T}$. dicoccoides genotypes were blotted onto Hybond N+ membranes (Amersham). The nonradioactive chemiluminescence method (Gene Images, Amersham) was used for probe labeling, hybridization, and detection of hybridization sites. The Revolver cDNA subfamily I (pSc5, 694 bp), which was conserved in Triticum species, was used as a probe. The membranes were hybridized at $60^{\circ} \mathrm{C}$ for $30 \mathrm{~min}$ in hybridization buffer and then hybridized with a labeled probe at $60^{\circ} \mathrm{C}$ overnight. The membranes were washed in SSC, $0.1 \%$ SDS at $60^{\circ} \mathrm{C}$ for $15 \mathrm{~min}$, then in $0.1 \times \mathrm{SSC}, 0.1 \% \mathrm{SDS}$ for 15 $\mathrm{min}$, followed by incubation for $60 \mathrm{~min}$ at room temperature in a $10 \%(\mathrm{w} / \mathrm{v})$ blocking agent in an antibody wash buffer. The membrane was then incubated in the presence of an anti-fluorescein antibody-alkaline phosphatase (AP) conjugate. The unbound conjugate was removed by three washes in $0.3 \%(\mathrm{v} / \mathrm{v})$ Tween 20 in an antibody wash buffer at room temperature. Hybridization sites were detected with the CDP-star detection reagent. Decomposition of the stabilized dioxetane was catalyzed by the probe-bound $\mathrm{AP}$, and exposure of the X-ray film by the emitted light was then recorded with a fluoro-image analyzer (FUJIFILM FLA-5000). The copy number was calculated on the basis of the most approximate function, which Image Gauge software computed from control slot blot hybridization to a series of measured amounts of Revolver cDNA $(0,10,100,1,000,5,000,10,000,15,000,20,000,30,000$, 50,000 , and 100,000 copies).

\section{Additional material}

Additional file 1: Three classes of Revolver mRNA. Revolver cDNAs obtained by RT-PCR, total lengths of 665 to $723 \mathrm{bp}$, were classified into three subfamilies wherein the regions of the second and third exons were almost identical, while the region of the first exon exhibited a low homology of $60 \%$ among the families because of duplication or deletion. Repetitive sequence units composed of 8 to $14 \mathrm{bp}$ are present in the same direction in the first exon as seen on the dot plot. Neighborjoining tree of Revolver cDNA sequences in the Triticeae indicated alongside species names showed major three clusters according to the three sub-families; numbers on branches indicate the boot strap values and homologies.

Additional file 2: Sequence alignment between authentic Revolver genomic clones from rye IR27 (Revolver-3, 5, 6: AB124641, 124643, 124644) and newly isolated Revolver genomic clones (Revolver-3 on Chr. 6R, Revolver-5 on Chr. 1R, Revolver-6 on Chr. 5R: AB646252646254) from each rye Imperial chromosome added in wheat. Each genomic clone localized on the chromosomes exhibits homology of 96 98\% between the genomes of IR27 and Imperial.

Additional file 3: Geographic distribution of 18 tested populations of wild emmer wheat at 15 sites in Israel. Populations 1-6 were collected from warm, semi-humid environments on the Golan Plateau and near the Sea of Galilee (Yehudiyya, Gamla, Ammiad, Rosh-Pinna, Tabigha, and Mt. Hermon). Populations 7-11 were collected across a wide geographic and marginal steppic area on northern, eastern, and southern borders of wild emmer distribution involving hot, cold, and xeric peripheries (Mt. Gilboa, Mt. Gerizim, Gitit, Kokhav-Hashahar, and J'aba). Populations 12-15 were collected from marginal Mediterranean areas, which are the humid western borders of wild emmer distribution (Amirim, Bet Oren, Bat Shelomo, and Giv'at Koah).

Additional file 4: Copy numbers of Revolver and geographic and climatologic data for 18 populations of Triticum dicoccoides in Israel. 


\section{Acknowledgements}

The authors acknowledge the Japanese Ministry of Education, Culture, Sports, Science and Technology (MEXT) for the Grant-in-Aid for Scientific Research No. 22580005 that supported this work to MT. We also thank Japan Science and Technology Agency (IST) for the Adaptable and Seamless Technology Transfer Program through Target-driven R \& D No. 08150094 that supported this work to MT. We thank Alex Beharav for statistical support and the Ancel Teicher Research Foundation of Molecular Evolution and Genetics for financial support to EN.

\section{Author details}

'Molecular Genetics Laboratory, Faculty of Agriculture, Tottori University, Tottori 680-8553, Japan. ${ }^{2}$ Institute of Evolution, University of Haifa, Mount Carmel, Haifa 31905, Israel.

\section{Authors' contributions}

MT conceived and designed the experiments. MT performed the experiments and analyzed the data in Figures 1, 2, 3, 4 and Additional files 1, 2. MT and $A O$ performed the experiments in Figure 5 and Additional file 4. $A B$ and $E N$ analyzed statistically the data in Figure 5 and Additional file 4. EN contributed the materials in Additional file 3. MT wrote the paper. All authors read and approved the final manuscript.

Received: 23 March 2011 Accepted: 25 September 2011

Published: 25 September 2011

\section{References}

1. Flavell RB, Rimpau JR, Smith DB: Repeated sequence DNA relationships in four cereal genomes. Chromosoma 1977, 63:205-222.

2. Grandbastien MA: Retroelements in higher plants. Trends Genet 1992, 8:103-108

3. Barakat A, Carels N, Bernardi G: The distribution of genes in the genomes of Gramineae. Proc Natl Acad Sci USA 1997, 94:6857-6861.

4. Panstruga R, Buschges R, Piffanelli P, Schulze-Lefert P: A contiguous $60 \mathrm{~kb}$ genomic stretch from barley reveals molecular evidence for gene islands in a monocot genome. Nucleic Acids Res 1998, 26:1056-1062.

5. SanMiguel P, Bennetzen JL: Evidence that a recent increase in maize genome size was caused by the massive amplification of intergene retrotransposons. Ann Bot 1998, 82:37-44.

6. Myers BC, Tingey SV, Morgante M: Abundance, distribution, and transcriptional activity of repetitive elements in the maize genome. Genome Res 2001, 11:1660-1676.

7. Bennetzen JL: Transposable element contributions to plant gene and genome evolution. Plant Mol Biol 2000, 42:251-269.

8. Vicient CM, Jaaskelainen MJ, Kalendar R, Schulman AH: Active retrotransposons are a common feature of grass genomes. Plant Physiol 2001, 125:1283-129.

9. Bureau TE, Ronald PC, Wessler SR: A computer-based systematic survey reveals the predominance of small inverted- repeat elements in wildtype rice genes. Proc Natl Acad Sci USA 1996, 93:8524-8529.

10. Zhang X, Jiang N, Feschotte C, Wessler SR: PIF- and Pong-like transposable elements: distribution, evolution and relationship with Tourist-like miniature inverted-repeat transposable elements. Genetics 2004 166:971-986.

11. Kumar A, Hirochika H: Applications of retrotransposons as genetic tools in plant biology. Trends in Plant Sci 2001, 6:127-134.

12. Lunde CF, Morrow DJ, Roy LM, Walbot V: Progress in maize gene discovery: a project update. Funct Integr Genomics 2003, 3:25-32.

13. Stein $\mathrm{N}$ : Triticeae genomics: advances in sequence analysis of large genome cereal crops. Chromosome Res 2007, 15:21-31.

14. Wicker T, Narechania A, Sabot F, Stein J, Vu GTH, Graner A, Ware D, Stein N: Low-pass shotgun sequencing of the barley genome facilitates rapid identification of genes, conserved non-coding sequences and novel repeats. BMC Genomics 2008, 9:518

15. Sunker R, Girke T, Zhu JK: Identification and characterization of endogenous small interfering RNAs from rice. Nucleic Acids Res 2005, 33:4443-4454

16. Feschotte C: Transposable elements and the evolution of regulatory networks. Nat Rev Genet 2008, 9:397-405.
17. Siomi H, Siomi MC: Interactions between transposable elements and Argonautes have (probably) been shaping the Drosophila genome throughout evolution. Curr Opin Genet Dev 2008, 18:181-187.

18. Tomita M, Shinohara K, Morimoto M: Revolver is a new class of transposon-like gene composing the Triticeae genome. DNA Res 2008 , 15:49-62.

19. Tomita M: Revolver-2: a novel transposon-like element from rye. United States Patent: 7351536B2, 2008.

20. Tomita M, Akai K, Morimoto T: Genomic subtraction recovers rye-specific DNA elements enriched in the rye genome. Mol Biotechnol 2009, 42:160-167.

21. Flavell AJ, Dunbar E, Anderson R, Pearce SR, Hartley R, Kumar A: Ty1-copia group retrotransposons are ubiquitous and heterogeneous in higher plants. Nucleic Acids Res 1992, 20:3639-3644.

22. Kumar A, Bennetzen JL: Plant retrotransposons. Annu Rev Genet 1999, 33:479-532.

23. Kunze R, Well CF: The hAT and CACTA superfamilies of plant transposons. In Mobile DNA II. Edited by: Craig NL, Craigie R, Gellert M, Lambowitz AM. American Society for Microbiology Press, Washington, DC; 2002:565-610.

24. Bennetzen JL: The Mutator transposable element system of maize. Curr Top Microbiol Immunol 1996, 204:195-229.

25. Feschotte C, Jiang N, Wessler SR: Plant transposable elements: where genetics meets genomics. Nat Rev Genet 2002, 3:329-341.

26. Feschotte $C$, Zhang $X$, Wessler SR: Miniature inverted-repeat transposable elements (MITEs) and their relationship with established DNA transposons. In Mobile DNA II. Edited by: Craig NL, Craigie R, Gellert M, Lambowitz, AM. American Society for Microbiology Press, Washington, DC; 2002:1147-1158.

27. Nevo E, Korol AB, Beiles A, Fahima T: Evolution of wild emmer and wheat improvement. Population genetics, genetic resources, and genome organization of wheat's progenitor, Triticum dicoccoides. Springer, Berlin; 2002, 364

28. Wicker T, Sabot F, Hua-Van A, Bennetzen JF, Capy P, Chalhoub B, Flavell A Leroy P, Morgante M, Panaud O, Paux E, Sanmiguel P, Schulman AH: A unified classification system for eukaryotic transposable elements. Nat Rev Genet 2007, 8:973-982.

29. Lisch D: Mutator transposons. Trends Plant Sci 2002, 7:498-504.

30. Nevo E, Beiles A: Genetic diversity of wild emmer wheat in Israel and Turkey. Theor Appl Genet 1989, 77:21-455.

31. Peng J, Ronin YI, Fashima T, Roder MS, Li Y, Nevo E, Korol AB: Domestication quantitative trait loci in Triticum dicoccoides, the progenitor of wheat. Proc Natl Acad Sci USA 2003, 100:2489-2494.

32. Vicient CM, Suoniemi A, Anamthawat-Jonsson K, Tanskanena J, Beharav A, Nevo E, Schulman AH: Retrotransposon BARE-1 and its role in genome evolution in the genus Hordeum. Plant Cell 1999, 11:1769-1784.

33. Kalendar R, Tanskanen J, Immonen M, Nevo E, Schulman AH: Genome evolution of wild barley (Hordeum spontaneum) by BARE-1 retrotransposon dynamics in response to sharp microclimatic divergence. Proc Natl Acad Sci USA 2000, 97:6603-6607.

34. Nevo E: Evolution of genome-phenome diversity under environmental stress. Proc Natl Acad Sci USA 2001, 98:6233-6240.

35. Grandbastien MA: Activation of plant retrotransposons under stress conditions. Trends Plant Sci 1998, 3:181-187.

36. Kumar A, Bennetzen JL: Plant retrotransposons. Annu Rev Genet 1999, 33:479-532.

37. Suoniemi A, Anamthawat-Jonsson $\mathrm{K}$, Arna T, Schulman AH: Retrotransposon BARE-1 is a major, dispersed component of the barley (Hordeum vulgare L.) genome. Plant Mol Biol 1996, 30:1321-1329.

38. Suoniemi A, Narvanto A, Schulman AH: The BARE-1 retrotransposon is transcribed in barley from an LTR promoter active in transient assays. Plant Mol Biol 1996, 31:295-306

39. Vernhettes S, Grandbastien MA, Casacuberta JM: In vivo characterization of transcriptional regulatory sequences involved in the defence-associated expression of the tobacco retrotransposon Tnt1. Plant Mol Biol 1997, 35:673-679.

40. Takeda S, Sugimoto K, Otsuki H, Hirochika H: Transcriptional activation of the tobacco retrotransposon Tto1 by wounding and methyl jasmonate. Plant Mol Biol 1998, 36:365-376.

41. Hirochika H: Activation of tobacco retrotransposons during tissue culture. EMBO J 1993, 12:2521-2528. 
42. Park ET, Kazazian HH Jr: Biology of manmmalian L1 retrotransposons. Annu Rev Genet 2001, 35:501-538.

43. Marillonnet $\mathrm{S}$, Wessler SR: Extreme structural heterogeneity among the members of maize. Genetics 1998, 150:1245-1246.

44. SanMiguel P, Gaut BS, Tikhonov A, Nakajima Y, Bennetzen JL: The paleontology of intergene retrotransposons of maize. Nature Genet 1998, 20:43-45.

45. Hamilton A, Voinnet O, Chappell L, Baulcombe D: Two classes of short interfering RNA in RNA silencing. EMBO J 2002, 21:4671-4679.

46. Llave C, Kasschau KD, Rector MA, Carrington JC: Endogenous and silencing-associated small RNAs in plants. Plant Cell 2002, 14:1605-1619.

47. Altschul SF, Madden TL, Schaffer AA, Zhang J, Zhang Z, Miller W, Lipman D: Gapped BLAST and PSI-BLAST: a new generation of protein database search programs. Nucleic Acids Res 1997, 25:3389-3402

48. Kumar S, Tamura K, Nei M: MEGA3: Integrated software for molecular evolutionary genetics analysis and sequence alignment. Briefings in Bioinformatics 2004, 5:150-163.

49. Saitou N, Nei M: The neighbor-joining method: A new method for reconstruction phylogenetic trees. Mol Biol Evol 1987, 4:406-425.

50. Kimura $\mathrm{M}$ : A simple method for estimating evolutionary rate of base substitution through comparative studies of nucleotide sequences. J Mol Evol 1980, 16:111-120.

doi:10.1186/1471-2148-11-269

Cite this article as: Tomita et al:: Genomic, RNA, and ecological divergences of the Revolver transposon-like multi-gene family in Triticeae. BMC Evolutionary Biology 2011 11:269.

\section{Submit your next manuscript to BioMed Central and take full advantage of:}

- Convenient online submission

- Thorough peer review

- No space constraints or color figure charges

- Immediate publication on acceptance

- Inclusion in PubMed, CAS, Scopus and Google Scholar

- Research which is freely available for redistribution

Submit your manuscript at www.biomedcentral.com/submit 